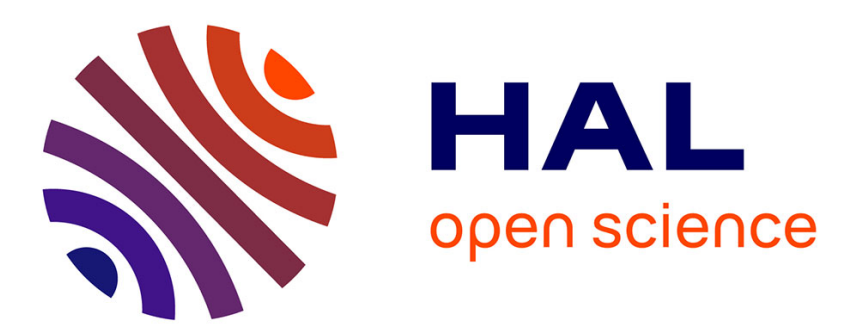

\title{
A monoallelic double mutation as a cause for TNF receptor-associated periodic fever syndrome
}

J. Trübenbach, G. Wildhardt, J. Niebel, H. Hawle, Daniela Steinberger

\section{To cite this version:}

J. Trübenbach, G. Wildhardt, J. Niebel, H. Hawle, Daniela Steinberger. A monoallelic double mutation as a cause for TNF receptor-associated periodic fever syndrome. Rheumatology International, 2009, 30 (6), pp.805-809. 10.1007/s00296-009-0996-2 . hal-00568296

\section{HAL Id: hal-00568296 \\ https://hal.science/hal-00568296}

Submitted on 23 Feb 2011

HAL is a multi-disciplinary open access archive for the deposit and dissemination of scientific research documents, whether they are published or not. The documents may come from teaching and research institutions in France or abroad, or from public or private research centers.
L'archive ouverte pluridisciplinaire HAL, est destinée au dépôt et à la diffusion de documents scientifiques de niveau recherche, publiés ou non, émanant des établissements d'enseignement et de recherche français ou étrangers, des laboratoires publics ou privés. 
Trübenbach $\mathrm{J}^{2}$, Wildhardt $\mathrm{G}^{2}$, Niebel $\mathrm{J}^{3}$, Hawle, $\mathrm{H}^{3}$, Steinberger $\mathrm{D}^{1,4}$

\title{
A monoallelic double mutation as a cause for TNF receptor associated periodic fever syndrome (TRAPS)
}

\author{
', bio.logis, Center for Human Genetics Frankfurt, Frankfurt, Germany \\ ${ }^{2}$ Bioscientia, Institut für Medizinische Diagnostik, Ingelheim, Germany \\ ${ }^{3}$ Deutsche Klinik für Diagnostik, Wiesbaden, Germany \\ ${ }^{4}$ Justus-Liebig University, Institute for Human Genetics, Gießen, Germany
}

\author{
Corresponding author: \\ Prof. Dr. med. Daniela Steinberger \\ bio.logis Center for Human Genetics \\ Altenhöferallee 3 \\ 60438 Frankfurt am Main, Germany \\ Tel: +496958092402 \\ Fax: +496958092436 \\ Email: daniela.steinberger@uni-giessen.de
}




\begin{abstract}
Hereditary periodic fever syndromes (HPFSs) are a subset of human autoinflammatory diseases characterized by periodic episodes of fever and signs of inflammation with or without involvement of inner organs. In this paper, we report phenotypic features of an index patient and affected family members that present a previously not described mutation type in the TNFRSF1A-gene. The phenotype of a HPFS of affected family members was shown to be associated with two monoallelic mutations in TNFRSF1A. Primarily, the index patient was clinically diagnosed as being affected by familial Mediterranean fever (FMF). However, with molecular genetic analyses it could be shown that the patient was in fact affected by tumor necrosis factor receptor-associated periodic syndrome (TRAPS), which requires a different therapy compared to FMF. Thus, molecular genetic analyses of currently known disease loci enable the most precise diagnosis presently available and are consequently the basis for the most effective therapeutic intervention.
\end{abstract}

\title{
Keywords
}

TRAPS, hereditary periodic fever syndrome, autoinflammatory syndromes, monoallelic mutation, TNFRSF1A 


\section{INTRODUCTION}

Recurrent fever episodes can develop from different hereditary and non-hereditary origins. The aetiology is often difficult to assess. Relevant non-hereditary factors are, in particular, neoplasias, infections, chronic systemic disorders, e.g. Morbus Crohn, or rheumatic diseases [1-2]. In case of persistent periodical fever attacks over a long time period, hereditary periodic fevers, also called autoinflammatory syndromes, should be considered in differential diagnosis.

Human autoinflammatory diseases are characterized by periodic episodes of fever and signs of inflammation with or without involvement of organs leading to symptoms such as arthritis, pericarditis, pleuritis, peritonitis, abdominal pain, or myalgia. The disease group includes syndromes such as familial Mediterranean fever (FMF), hyperimmunoglobulinemia D with periodic fever syndrome (HIDS) and tumor necrosis factor receptor-associated periodic syndrome (TRAPS). Among the hereditary periodic fever syndromes, FMF and HIDS are autosomal recessively inherited, while TRAPS has a dominant mode of transmission. FMF is caused by mutations in the $M E F V$ (for MEditerranean FeVer)-gene [3], HIDS by mutations in the mevalonate kinase ( $M V K)$-gene [4], and TRAPS develops due to mutations in the Tumor Necrosis Factor Receptor Superfamily Member 1A (TNFRSF1A)-gene. The latter is encoding for the $55 \mathrm{kDa}$ TNF receptor TNFRSF1A, an archetypal proinflammatory receptor and member of a large group of proteins with homology in their extracellular domain [5-7].

While each syndrome has a specific genetic background and some phenotypic characteristics, all HPFS share a quite similar clinical expression that makes diagnosis based alone on clinical features more difficult [8]. Hence, often affections remain unrecognized and undiagnosed for years. During the last decade molecular studies revealed important progresses for the understanding of HPFSs [7-11]. Recent advances in molecular techniques have led to the identification of mutations that occur in several genes and are the underlying causes for these syndromes.

Here we report on phenotypic features of an index patient and other affected family members that presented a previously not described mutation type in the TNFRSF1A-gene. The phenotype of the affected family members was shown to be associated with two mutations in TNFRSF1A, and as we demonstrated, they were 
present in a monoallelic state in all affected family members. Primarily, the index patient was clinically diagnosed as being affected by familial Mediterranean fever [12]. With molecular genetic analyses it could be shown that the patient was in fact affected by TRAPS. This molecular diagnosis had relevant consequences since it resulted in reconsidering the further therapy.

\section{Case report}

A 36 year old patient (index III:2, fig. 1) with German ancestry came for clarification of recurrent febrile attacks. He reported recurrent episodes of abdominal pain and fever since the age of 7 years. After a severe fever attack at the age of 10 accompanied by colicky abdominal pain and ongoing fever episodes for 2-4 days, familial Mediterranean fever (FMF) was diagnosed due to characteristic signs and symptoms. Typical laboratory biochemical findings indicated an inflammatory episode. Laparoscopy showed histologically a fibrinous purulent peritonitis.

In the course of his life, symptoms within intervals of affection diminished. Acute febrile episodes occurred three to four times a year accompanied by chill, general sensation of being ill, abdominal pain, headache and pain in limb muscle groups. Independent of this pathology, he suffered from recurrent pain of the flanks without fever, dysuria and gross hematuria. For medication, Indometacin (maximum of $150 \mathrm{mg} / \mathrm{d}$ ) was administered on demand. Currently, disease episodes occur approximately once every two years for 7-21 days with an increase in temperature up to $40{ }^{\circ} \mathrm{C}$.

Noteworthy, the patient's father at adolescence as well as his aunt and several cousins were affected by similar fever symptoms (fig. 1). For further clarification, molecular genetic analyses of the $M E F V$-, $M V K$ - and TNFRSF1A-gens were performed. 


\section{METHODS}

\section{Clinical description}

At the time of physical examination, the patient $(185 \mathrm{~cm}, 83 \mathrm{~kg})$ was in good general condition. The abdomen was soft without resistances and palpation gave no hint for a renal affection. A neurological examination showed regular findings. Laboratory results showed an increased erythrocyte sedimentation rate $(44 / 64 \mathrm{~mm})$ and a normal hemogram. Further diagnostic examinations, such as sonography of the abdomen, echocardiography and a rectum biopsy revealed regular findings, and were not suggestive of amyloidosis.

\section{Molecular genetic analyses}

DNA was extracted from peripheral blood of the patients and controls according to standard procedures using the QIAamp DNA Blood Mini Kit (Qiagen, Hildesheim, Germany). Sequence analyses were undertaken according to standard protocols.

For index patient III:2 the genes $M E F V, M V K$ and TNFRSF1A were analyzed completely. Subsequent to the findings in exon 4 of TNFRSF1A and exon 2 of $M V K$ for the index patient, the clinically suspicious family members II:3 and III:1 and the healthy mother II:4 were also analyzed for these alterations.

\section{RESULTS}

For the index patient, two nucleotide substitutions in exon 4 of TNFRSF1A were detected via sequencing of the coding region: first, the amino acid substitution guanine to cytosine at position 263 of the nucleotide sequence (c.263G $>$ C), and second, the substitution of cytosine to adenine at position 264 (c.264C>A). Both alterations were detected as heterozygous, which means a nucleotide of the normal wildtype sequence was apparent on one allele, and the substitutions on the other (fig. 2). Molecular genetic analysis of the complete $M E F V$-gene (associated with FMF) and the $M V K$-gene (associated with the clinical phenotype HIDS) revealed no indication for disease causing mutations. However, in the $M V K$-gene a $\mathrm{G}>\mathrm{A}$ transition (c. $155 \mathrm{G}>\mathrm{A}$ ) resulting in the amino acid substitution serine to 
asparagine (p.Ser52Asn) was shown to be present in heterozygous state for the index patient and other affected family members studied. This alteration is described to represent a common polymorphism [11].

After molecular analyses of the index patient only, the question could not be answered whether one gene copy was affected by both mutations (monoallelic), or each gene copy by one mutation (compound heterozygosity). Hence, for clarification, both parents of the index patient (father II:3 and mother II:4; see fig. 1) as well as the paternal cousin (III:1) were molecular genetically analyzed. The analyses of the patient's parents revealed that the father carries the same two alterations and the mother a wildtype sequence. With the molecular genetic analysis of the patient's affected cousin III:1 the same genotype as for II:3 (father) and III:2 (index patient) was identified. Thus, it could be concluded that both mutations were inherited in a monoallelic mode. Given the newly obtained information on the allelic distribution of mutations, it is likely that the nucleotide substitutions resulted in the transformation of the triplet TGC to TCA, which consequently results in the amino acid substitution cysteine to serine at position 88 of the protein (p.Cys88Ser; fig. 3). The substitutions affect the cysteine-rich domain 2 (CRD 2) of TNFRSF 1A and interfere most likely with the tertiary structure of the receptor by eliminating a disulfide bridge (fig. 4).

\section{DISCUSSION}

The mutations in TNFRSF1A detected in our study have previously not been described, neither as single entities nor as a combination. They were detected as heterozygous appearing signals which could be proven to have occurred in a monoallelic state. Hence, they result in the amino acid substitution cysteine to serine at position 88 of the protein (p.Cys88Ser). Cysteine at position 88 is located in the second extracellular, cysteine-rich subdomain (CRD2) of the TNFRSF1Aprotein. The cysteine-motif of this domain is well-conserved and occurs homologous in different species. Cysteine is essential for the formation of disulfide bonds, and thus in the formation of the protein specific tertiary structure (fig. 3) [7]. The putative affect of this amino acid substitution reported above is the disintegration of a disulfide bridge in the cysteine-rich domain 2 (CRD2) of TNFRSF1A. Most probably, this results in the disruption of the tertiary structure, 
thus leading to functional disturbance of the protein. This in turn leads consequently to signs and symptoms of a distinct form of a hereditary periodic fever syndrome that can be - based on the molecular findings - classified as TRAPS. TRAPS formerly known as familial Hibernian fever, was first described as a distinct nosologic entity by McDermott MF in 1999 [7]. It is classified as one of the hereditary periodic fever syndromes, which are a group of autoinflammatory diseases with clinical symptoms that are variable and tend to overlap in a broad spectrum. For TRAPS, relapsing and remitting disease episodes are characteristic, and the onset of disease tends to be later and the duration of the attacks longer than in other HPFSs. This is in particular true for FMF. Episodes of fever typically last 7 to 21 days accompanied by abdominal pain, polyserositis (in most cases peritonitis), lymphadenopathy, myalgias, chest pain, skin manifestations, periorbital edema and rashes as well as conjunctivitis. The disease is very similar to FMF, but can be discordant in the length of fever attacks (7-21 days). Most severe forms of TRAPS show almost permanent clinical signs of inflammation and require daily use of therapy. TRAPS occurs frequently already in childhood and early adolescence, and in general the severity of episodes diminish in the course of life. For therapy, treatment with corticosteroids is recommended to attenuate the length and severity of attacks. Treatment with corticosteroids is usually ineffective in patients that are affected by FMF [5-6]. Furthermore, patients with TRAPS seem to benefit from TNF inhibitors, e.g. Etanercept, which mimics the effect of normal soluble TNF receptor and thus compensates for its deficit.

Most TRAPS-associated mutations have been identified to be of the missense type and are located predominantly within the first or second cysteine-rich $\mathrm{N}$-terminal extracellular domain (CRD1 and CRD2) of the receptor [6, 13]. Recent studies concentrate on the mechanism of TRAPS signaling pathways and discuss new findings describing aberrant trafficking and function of TNFRSF1A harboring TRAPS mutations, challenging the hypothesis that TRAPS pathology is driven by defective receptor shedding [13]. It is suggested that TNFRSF1A might acquire novel functions in the endoplasmatic reticulum, distinct from its role as a cell surface receptor. The systemic inflammation that is characteristic for TRAPS could result from the consequences of misfolded and intracellularly retained 
TNFRSF1A. However, the large variability of clinical symptoms could be an indication that there is no one unifying mechanism for all TRAPS mutations. In this study, we detected TRAPS mutations by molecular genetic analyses of a family that had shown periodic fever episodes, which were formerly classified as a potentially rare form of autosomal dominant FMF [12]. However, the initial diagnosis could be stated at this time alone by clinical observations and respective conclusions. In general, clinical phenotypes of hereditary fever syndromes are not specific for a distinct fever entity and show a remarkable overlap in symptoms. Thus, molecular genetic analyses of currently known disease loci enable the most precise diagnosis presently available and are consequently the basis for the most effective therapeutic intervention. In the present report, particularly in regards to further therapy, the diagnostic differentiation of TRAPS from the other HPFSs and from the previously diagnosed FMF was very important. Hence, a therapy with colchicine - known as an effective treatment in FMF but not in TRAPS - was not recommended for further disease episodes. Instead, steroids (Prednisolone 1$2 \mathrm{mg} / \mathrm{kg}$ body weight) and alternatively NSAIDs (Indometacin) are a preferred and effective treatment in this case.

\section{Acknowledgements}

Investigation of probands was performed according to the principles of the World Medical Association Declaration of Helsinki (WMA, General Assembly, 2004). We thank Andrea Rathmann-Schmitz for her assistance in preparing the manuscript for publication. 


\section{REFERENCES}

1. Timmann C, Schumacher J, Lamprecht P, Sudeck H, Horstmann R (2004) Genetisch bedingte Fiebersyndrome. Dtsch Arztebl 101(48):A3262-A3269.

2. Gattorno M, Federici S, Pelagatti MA, Caorsi R, Brisca G, Malattia C, Martini A (2008) Diagnosis and management of autoinflammatory diseases in childhood. J Clin Immunol 28:73-83 Medline. doi:10.1007/s10875-008-9178$\underline{3}$

3. Pras E, Aksentijevich I, Gruberg L, Balow JE Jr, Prosen L, Dean M, Steinberg AD, Pras M, Kastner DL (1992) Mapping of a gene causing familial Mediterranean fever to the short arm of chromosome 16. N Engl J Med 326:1509-1513 Medline.

4. Houten SM, Koster J, Romeijn GJ, Frenkel J, Di Rocco M, Caruso U, Landrieu P, Kelley RI, Kuis W, Poll-The BT, Gibson KM, Wanders RJ, Waterham HR (2001) Organization of the mevalonate kinase (MVK) gene and identification of novel mutations causing mevalonic aciduria and hyperimmunoglobulinaemia D and periodic fever syndrome. Eur J Hum Genet 9:253-259 Medline. doi:10.1038/sj.ejhg.5200595

5. Galon J, Aksentijevich I, McDermott MF, O'Shea JJ, Kastner DL (2000) TNFRSF1A mutations and autoinflammatory syndromes. Curr Opin Immunol 12:479-486 Medline. doi:10.1016/S0952-7915(00)00124-2

6. Hull KM, Drewe E, Aksentijevich I, Singh HK, Wong K, McDermott EM, Dean J, Powell RJ, Kastner DL (2002) The TNF receptor-associated periodic syndrome (TRAPS): emerging concepts of an autoinflammatory disorder. Medicine (Baltimore) 81:349-368 Medline. doi:10.1097/00005792200209000-00002

7. McDermott MF, Aksentijevich I, Galon J, McDermott EM, Ogunkolade BW, Centola M, Mansfield E, Gadina M, Karenko L, Pettersson T, McCarthy J, Frucht DM, Aringer M, Torosyan Y, Teppo AM, Wilson M, Karaarslan HM, Wan Y, Todd I, Wood G, Schlimgen R, Kumarajeewa TR, Cooper SM, Vella JP, Amos CI, Mulley J, Quane KA, Molloy MG, Ranki A, Powell RJ, Hitman GA, O'Shea JJ, Kastner DL (1999) Germline mutations in the extracellular domains of the $55 \mathrm{kDa}$ TNF receptor, TNFR1, define a family of dominantly inherited autoinflammatory syndromes. Cell 97:133-144 Medline. doi:10.1016/S0092-8674(00)80721-7

8. Yao Q, Furst DE (2008) Autoinflammatory diseases: an update of clinical and genetic aspects. Rheumatology 47:946-951 Medline. doi:10.1093/rheumatology/ken118

9. The International FMF Consortium (1997) Ancient missense mutations in a new member of the RoRet gene family are likely to cause familial Mediterranean fever. Cell 90:797-807 Medline. doi:10.1016/S0092$\underline{8674(00) 80539-5}$

10. Aksentijevich I, Torosyan Y, Samuels J, Centola M, Pras E, Chae JJ, Oddoux C, Wood G, Azzaro MP, Palumbo G, Giustolisi R, Pras M, Ostrer H, Kastner DL (1999) Mutation and haplotype studies of familial mediterranean fever 
reveal new ancestral relationships and evidence for a high carrier frequency with reduced penetrance in the Ashkenazi Jewish population. Am J Hum Genet 64:949-962 Medline. doi:10.1086/302327

11. Cuisset L, Drenth JPH, Simon A, Vincent MF, van der Velde Visser S, van der Meer JWM, Grateau G, Delpech M, International Hyper-IgD Study Group (2001) Molecular analysis of $M V K$ mutations and enzymatic activity in hyperIgD and periodic fever syndrome. Eur J Hum Genet 9:260-266 Medline. doi:10.1038/sj.ejhg. 5200614

12. Hawle H, Winckelmann G, Kortsik CSF (1989) Familial mediterranean fever in a German family. Dtsch Med Wochenschr 114:665-668 Medline. doi:10.1055/s-2008-1066652

13. Kimberley FC, Lobito AA, Siegel RM, Screaton GR (2007) Falling into TRAPS - receptor misfolding in the TNF receptor 1-associated periodic fever syndrome. Arthritis Res Ther 9:217 Medline. doi:10.1186/ar2197 


\section{FIGURE LEGENDS}

Fig. 1: Pedigree of the index patient's (*) family.

Fig. 2: Electropherogram of sequence analysis of TNFRSF1A for the index patient. The exchanges G263C and C264A are indicated by an arrow.

Fig. 3: Schematic presentation of the TNFRSF1A-gene structure. The nucleotide changes $\mathrm{G}>\mathrm{C}$ and $\mathrm{C}>\mathrm{A}$ are shown in red. The monoallelic presence of these mutations results in the amino acid change cysteine to serine at position 88 of the protein sequence.

Fig. 4: Schematic presentation of the functional domains of the TNFRSFIA protein. The extracellular disulfide bonds of TNFRSF1 are numbered according to Mc Dermott et al., 1999 and are shown as lines connecting conserved cysteine residues (5 and 6) [7]. The position of the mutated amino acid is marked with an asterisk. Substitution occurred in the cysteine-rich domain 2 (CRD2) of TNFRSF1A. This is most probably altering the tertiary structure of the receptor by eliminating the disulfide bridge 5 .

Fig. 1

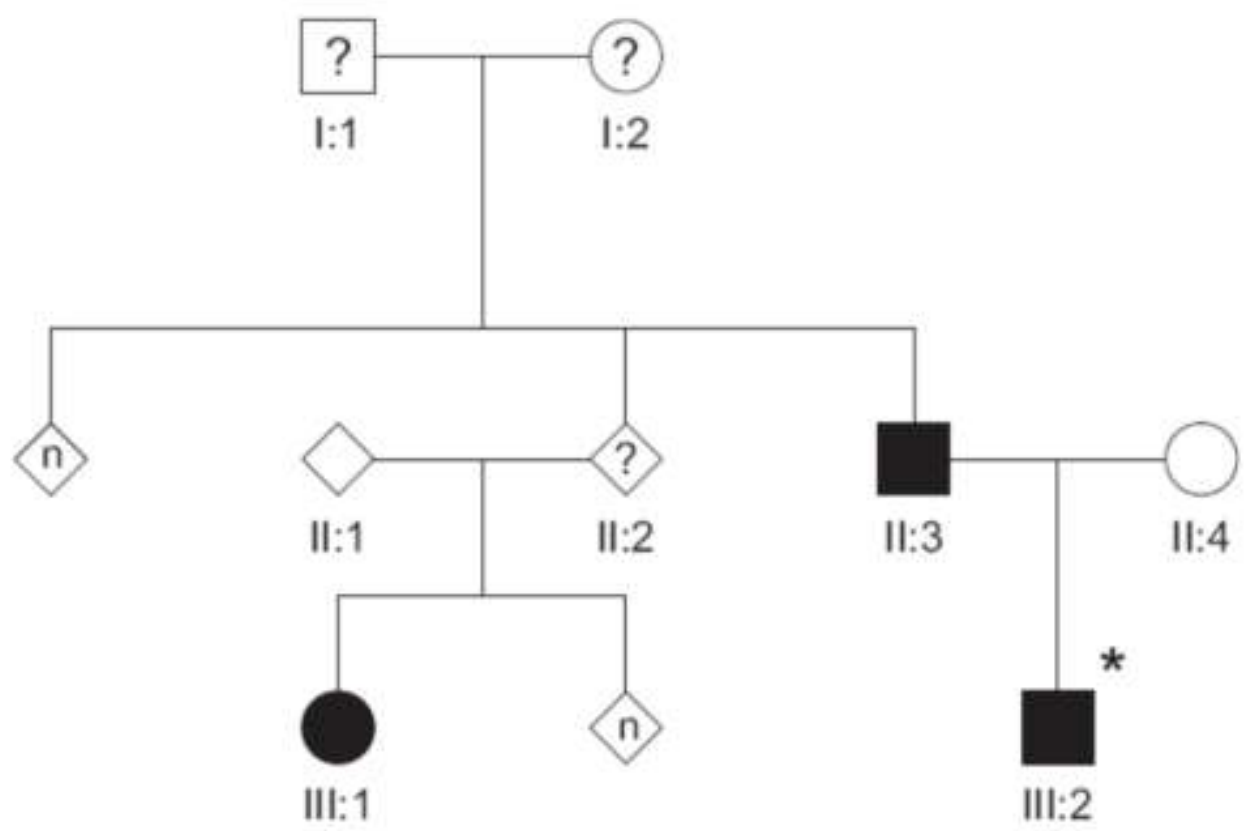


Fig. 2

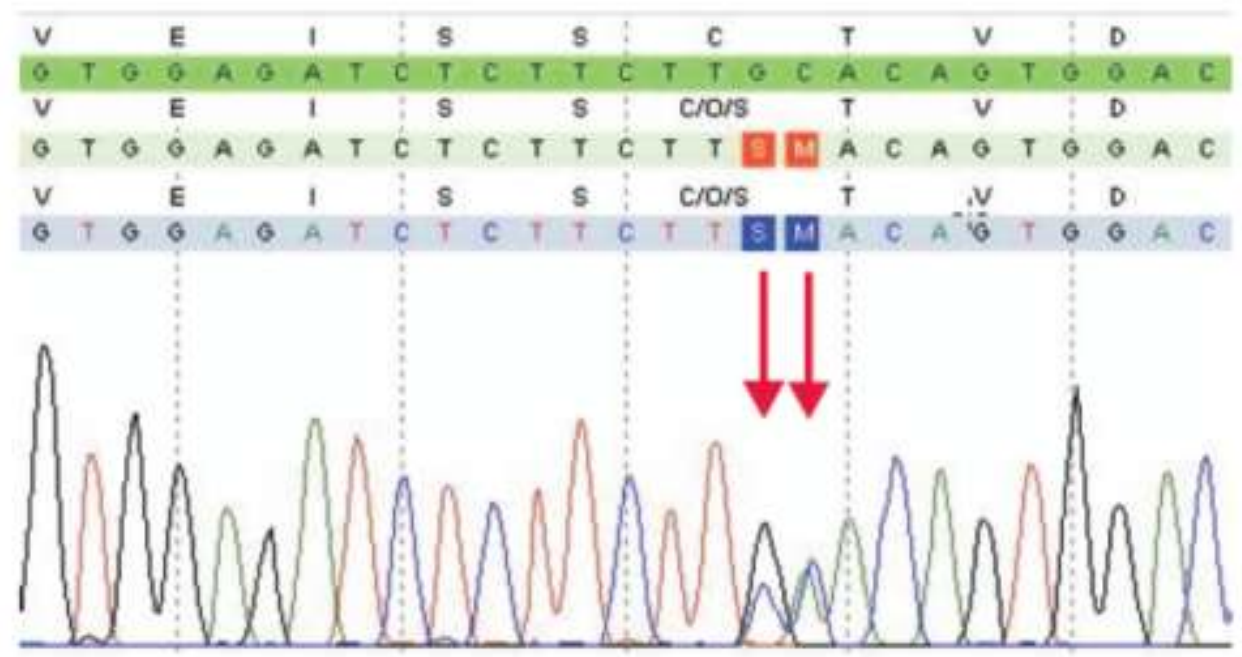

Fig. 3

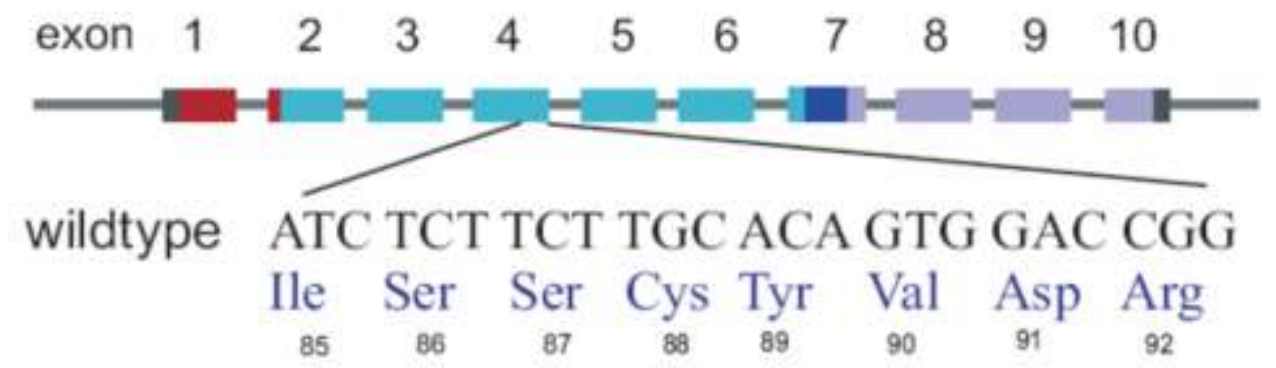
mutation ATC TCT TCT TCA ACA GTG GAC CGG Ile Ser Ser Ser Tyr Val Asp Arg

Fig. 4 


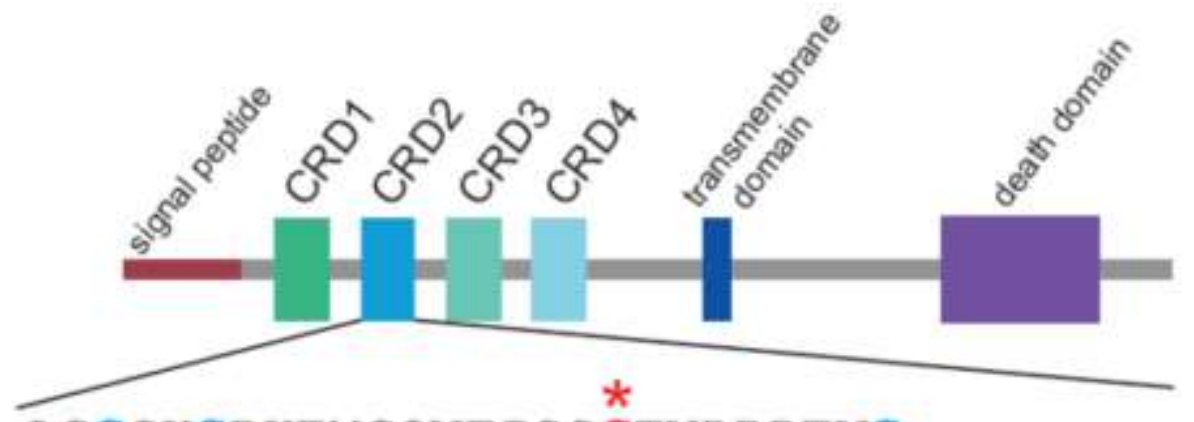

LSCSKCRKEMGQVEISSCTVDRDTVC

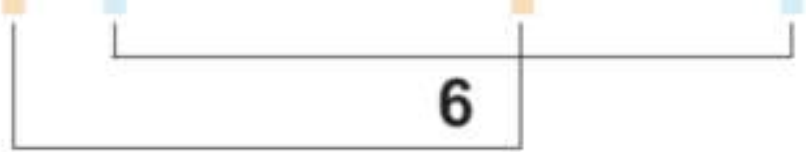

5 